\title{
Strategies for the Development of Smart Cities: The Case of Kalampaka-Greece
}

\author{
Christos Stamopoulos (Corresponding author) \\ Dept. of Home Economics and Ecology, Harokopio University \\ PO Box 17676, Kallithea, Greece \\ Tel: 00302109549205 E-mail: cstamopoulos@hua.gr \\ Eleni Theodoropoulou \\ Dept. of Home Economics and Ecology, Harokopio University \\ PO Box 17676, Kallithea, Greece
}

Tel: 00302109549205 E-mail: etheodo@hua.gr

Received: February 6, 2018

doi:10.5296/ijrd.v5i1.12645
Accepted: March 28, 2018 Published: May 16, 2018

URL: http://dx.doi.org/10.5296/ijrd.v5i1.12645

\begin{abstract}
The present paper investigates the characteristics and best construction strategies of smart cities around the world, as well as the determining factors of the satisfaction of the quality of life and the importance of the value of environmental sustainability. A case study of the city of Kalampaka and its residents was examined. The survey was conducted between July 2016 and August 2016. The selection of the sample was done by using the method of simple selection and includes a random sample of $\mathrm{N}=150$ individuals. Statistical analysis showed that resident's knowledge about smart cities was fairly good (48\% of sample knew the phrase "smart cities"). Furthermore, they believe that the appearance of the city of Kalampaka needs improvement ( $75 \%$ of sample is disappointed with the current appearance of the city). Regression analysis showed that the value of environmental sustainability is greatly influenced by the energy saving, as well as, innovation has an impact on the level of quality of life. Older people seem to be satisfied with administration's efforts.
\end{abstract}

Keywords: Smart City, Development, Economy, Environment, Governance, Quality of Life

\section{Introduction}

Smart city is a phenomenon which appeared especially because of the technological evolution. Cities become flexible, making people's life easier. Instead of that environmental sustainability is a priority for everyone. The physiognomy of the cities changes all over the 
time. It developed a worldwide trend to concentrate a large part of the population in urban cities. As a result, some negative aspects created (for example traffic congestion, problems in waste management etc) making necessary the demand of innovative solutions. Taking into account, also, the forms of competition that exist between the countries, these challenges have to led experimentation with new approaches to the design, financing, construction, urban infrastructure and governance. That's why the phenomenon of smart cities began appearing in recent decades (Harrison et al, 2011). The strategies, which used to build smart cities, based on characteristics such as economy, management, living, mobility, environment, humans. However, there are differences from one city to another (Angelidou, 2016). Every city has specific characteristics and history. By using them, a smart city ensures an integrated endogenous development of social life and society's sustainability. Of course, to get to this point, it's required the participation of the citizens and more investment in education and entrepreneurship (Keta, 2015). Smart cities are a part of the broader project for western societies. Created from the combination of local innovation systems (technological districts, technological parks, innovation poles, clusters), they describe an environment that enhances human capabilities, creativity and learning. Their value lies in the ability to collect and combine three types of intelligence: 1) human which comes from urban population, 2) collective, which comes from innovation institutions and 3) artificial, which come from digital networks and applications (Komninos, 2007; Florida, 2002). The cities need an identity. None of them can be good at all but the key which would help to increase the economic development and competitiveness is the new innovative ideas. As result, new funds and investments are attracted and the quality of life is improving. Furthermore, a "road" map of implementation is necessary to provide guidance about how to organize a smart city and creating the specifications for a strong brand name (Mochianakis, 2013).

\section{Literature Review}

Many approaches have occasionally expressed by researchers about how the cities can evolve. According to the characteristics of each city, it's given a priority to another sector. Also, particular emphasis must be given on the piece of technology and innovation which give additional solutions and make not only human's life but also the administration's activities easier (Hollands, 2008). Letaifa (2015) gave some examples about that. As mentioned, London was focusing on the piece of mobility, Montreal on the piece of health and networks and Stockholm on the piece of traffic management in the city center and replacement of the old infrastructure. In a similar way, Paris and Nice tried to encourage the quality of life, attracting new investors and creating prospects for start-up businesses (Arduin et al, 2016). The central administration has an important role for the implementation of such actions and a strategy will strengthen the coordination, monitoring and encouraging the rapid uptake of smart cities' initiatives (Lee et al, 2013). Another example is mentioned by Borsekova et al (2015), who gave information about the potentially smart city Banska Bystica in Slovakia and found that all components in a smart city are interrelated and complement with each other. Fairly important is also the concern about the environmental protection (Ferrara, 2015) and the reduction of $\mathrm{CO}^{2}$ emissions consider necessary (a characteristic example is the promotion of photovoltaic panels of the city of Tokyo) (Yamagata et al, 2013). Kumar (2015) believes that experience and knowledge, which can be found though cooperation with foreign partners, 
enchase the development of smart cities. A striking example is the Songdo which is supported by institutions and that's the main reason USA experiment in new technologies there (Ksherti et al, 2015). Apart from that, the active participation of the citizens is equally important in the process of the development of smart cities. In the research of Kolokytha et al (2015) mentioned the availability of smart administration services improves this participation. Also, smart traffic system brings better air quality, reduced congestion and increased the use of public transportation (the case of Stockholm). Furthermore, it should be intertwined with the history and cultural heritage of each city using the experience without altering retrospectively (Edo- Period) (Pham, 2015). All the above could not operate without an intergraded economic approach which is the most important part in a smart city and that's why should be given the appropriate attention (Poloncarz, 2013; Hu et al, 2014).

\section{Methodology}

The choice of the city of Kalampaka was based on the specific attributes and its natural wealth. In the research, the selected sample was not only inhabitants of Kalampaka but also people who may not stay permanently but work there. The method, which used, was simple random sampling using a questionnaire. It was tested for the form, language, clarity of the difficulty and reliability in pilot study that preceded the main sampling (Oppenheim, 1992). It's a step, which seeks to investigate a) if the questions are understood, b) whether each question provides the information for which it was designed and c) if it ensures the interest and cooperation of respondents. After the above test-survey, the questionnaire was corrected and tested again before the main sampling, to achieve further improvement. It was collected a sample of $\mathrm{N}=150$ between July 2016 and August 2016. The research sections used for the survey are the following: 1) demographic characteristics, 2) smart cities' section, in which we investigated the knowledge of the respondents about smart cities and how they evaluate their characteristics, 3) the respondents expressed their opinion on the current appearance of the area and justify it. Instead of that, it was examined their opinion about environment's sensitivity and their satisfaction on the quality of the city's life and the determinants which affect them. The statistical data processing was done by SPSS and STATA.

\section{Empirical Results}

\subsection{Statistical Analysis}

The results of the sampling showed that the $52 \%$ of respondents were higher education graduates and the $38.3 \%$ reported that they have income up to 6000 euro and the $35.6 \%$ up to 15000 euro. About the level of knowledge of smart cities, the $48 \%$ knew the phrase "smart city", emphasizing on quality of life, environmental sustainability and energy saving. A significant factor in smart city considers the innovation (46\%) as well as the digital technology (49\%). Respondents were asked about the kind of innovations which they believe that can be implemented in a smart city. Energy efficiency innovations got the most positive answers (30\%) and followed by social with $22.7 \%$, infrastructure with $18.7 \%$, administrative with $14.7 \%$ and last techniques by $14 \%$. As to the values, respondents felt that quality of life will be affected most of all, the appearance of the city comes second and followed by financial gains for businesses, financial gains of the city and infrastructure. A huge 
percentage doesn't agree with the current appearance of the city $(75 \%)$, as also believes that there isn't environmental awareness (69\%), with the piece of recycling and enhancement of the quality of life, and are qualified as necessary solutions. It became obvious that the most important thing for city's economy is the tourism (71\%), with industrial enterprises $(14 \%)$ and agriculture sector (12\%) following. It would be expected that the city's condition could be better because of its tourism strong characteristic which are the holy rocks of Meteora. However the results showed the opposite. The employment opportunities are limited $(55 \%$ of respondents thought that are limited) and the economy doesn't have these elements that could provide the necessary motivation, like entrepreneurship and innovative spirit. Instead of that, there is strong dissatisfaction for the progress of municipality (66\% of the sample is not pleased by it). In order to give solutions for these problems, public administration should have greater participation in public life (35.4\%) and digital applications must be implemented $(32.3 \%)$ to facilitate the customer service. In this way, it could somehow cover the deficit that exists in the part of the services because of the mergers of departments in larger cities. At last, the respondents said if they are satisfied with the quality of life of the city. The results showed that the $73 \%$ responded negatively. Some of the facilities which they think that must be improved are the health facilities (23.4\%), the cultural facilities and social services such as kinder gardens, nursing home, help at home etc. (19.8\%).The tourist attractiveness received by each of $18.9 \%$ and behind come the local trade support (11.7\%) and educational facilities $(5.4 \%)$. Finally there was a small percentage that gave its own proposal $(1.8 \%)$ and had to do with the creation of sport facilities as well as relevant activities which will appeal to all the ages.

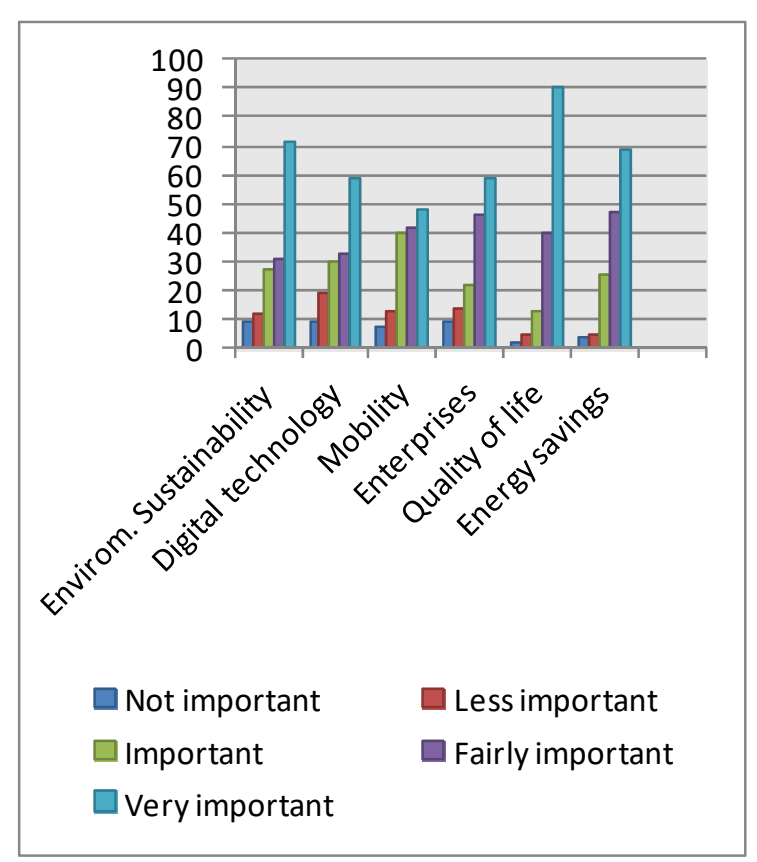

Graph 1. Values of smart cities (rating 1-5, where 1 not important to very important)

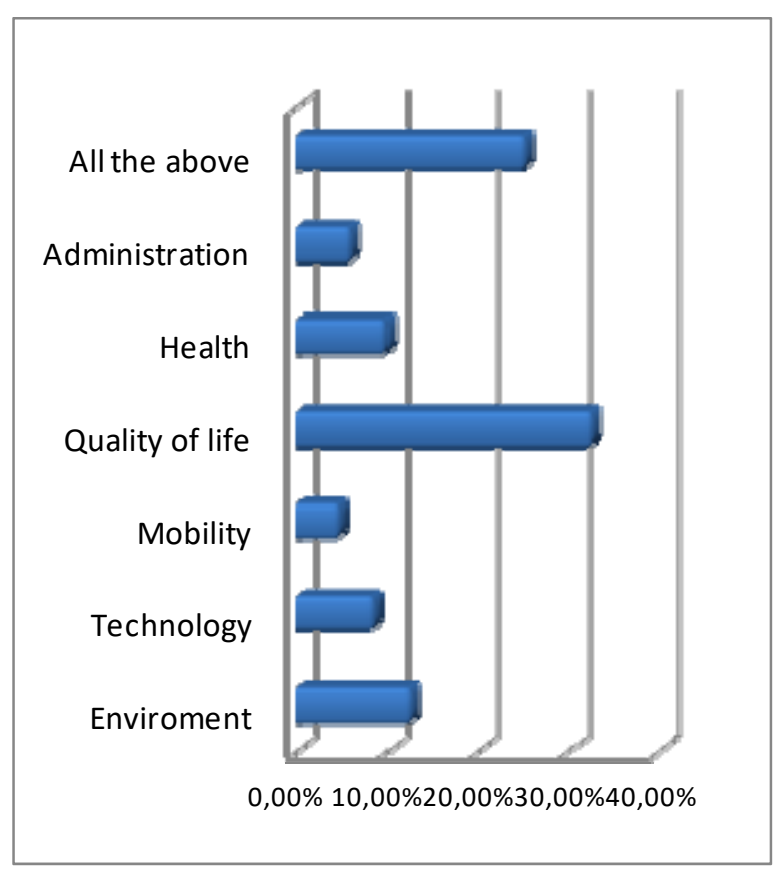

Graph 2. Sectors which need improvements primarily 


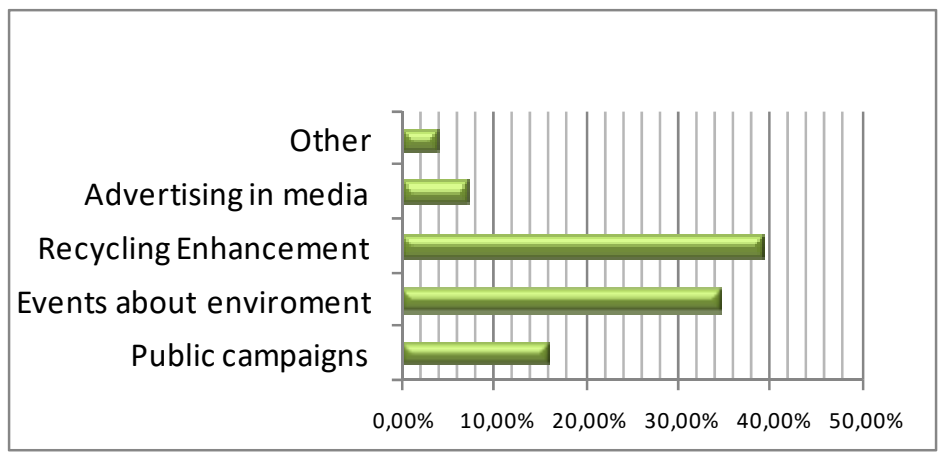

Graph 3. Methods that would help towards environmental awareness

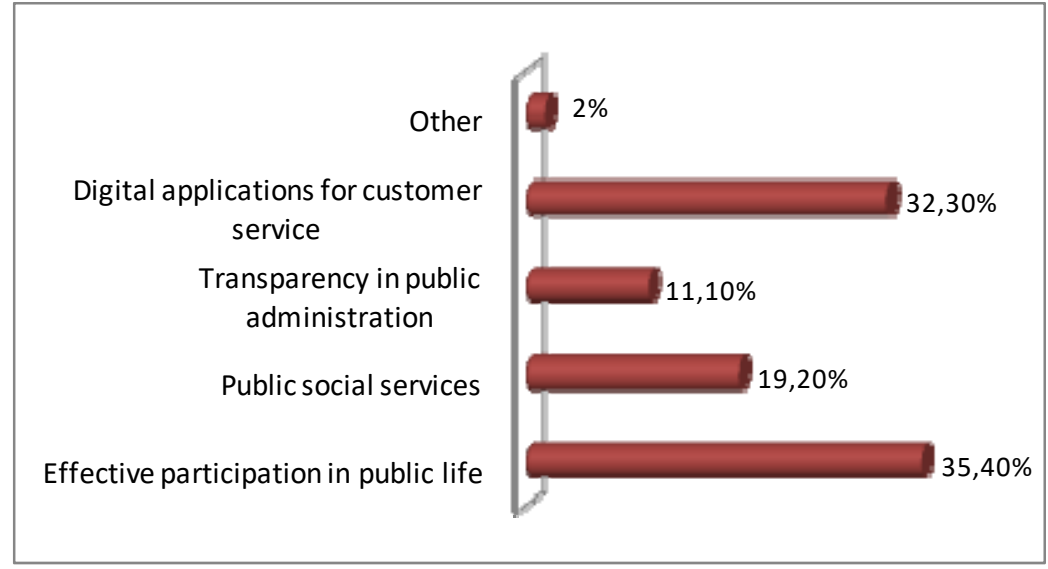

Graph 4. What do you think should be corrected to make better the city?

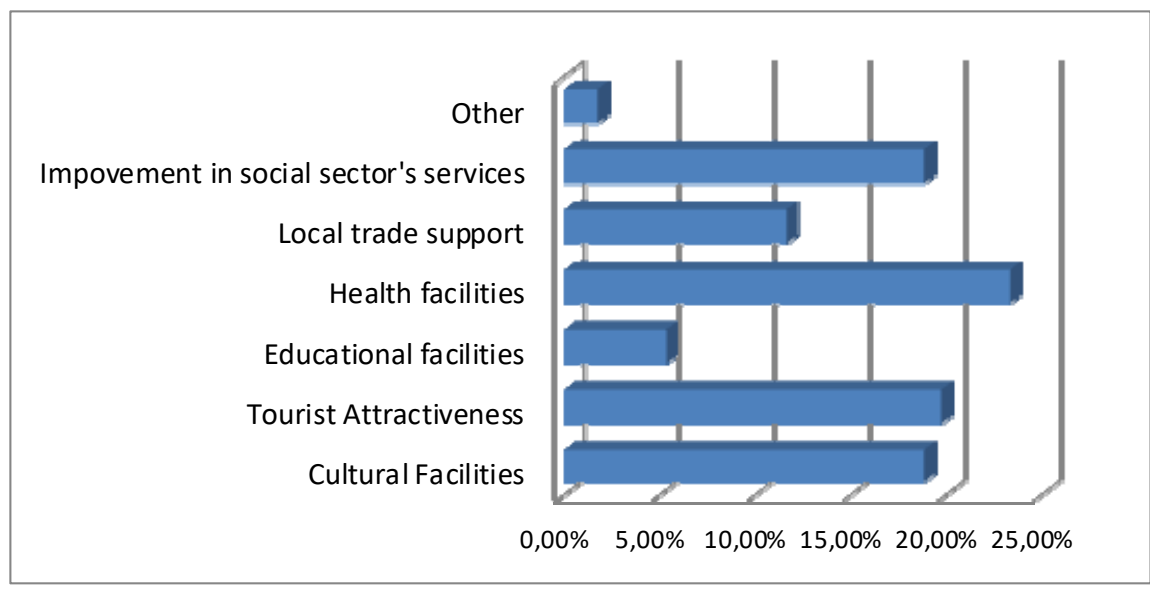

Graph 5. What do you think can improve the quality of city life?

\subsection{Econometrical Analysis}

After the descriptive analysis of the survey results, two cases are assessed of: the first one was about the determinants which affect the respondents' opinion about the value of environmental sustainability and the second case was about the determinants which influence the respondents' satisfaction on the quality of the city life. 


\section{Macrothink}

Journal Title International Journal of Regional Development

ISSN 2373-9851

2018, Vol. 5, No. 1

4.2.1 Determinants Affecting How Important Respondents Find the Value of Environmental Sustainability

The functional expression of the ordered logistic regression that estimated is:

$$
\text { sustenvir }=b_{0}+b_{1} \text { government }+b_{2} \text { qualitylife }+b_{3 \text { energy }}+b_{4} \text { innovinfra }+b_{5 \text { innovviewcity }}+\varepsilon_{i}
$$

In which

sustenvir Dependent qualitative variable, which expresses how important they find the value of environmental sustainability respondents from 1 to 3 , where $1=$ not important, $2=$ important, 3 = very important

government Independent dummy variable, which takes the value 0 if the respondent is not satisfied with the municipality and the value 1 otherwise

qualityoflife Independent qualitative variable, which measures the significance of this value (quality of life) of 1-5, where 1 to 5 not important very important

energy Independent qualitative variable, which measures the significance of this value (energy saving) from 1-5, where 1 to 5 not important very important

innovinfra Independent qualitative variable, which measures in which areas (infrastructure) can bring improvements innovations from 1-5, with 1 the lowest and 5 the highest

innovviewcity Independent qualitative variable which counts the areas in which improvements can bring innovations from 1-5, with 1 the lowest and 5 the highest

\&i expresses regression estimation errors.

Table 1. Results of the ordered logistic regression

\begin{tabular}{|c|c|c|c|c|c|}
\hline $\begin{array}{l}\text { Independent } \\
\text { Variables }\end{array}$ & $\begin{array}{l}\text { Estimated } \\
\text { Coefficients }\end{array}$ & Odd Ratio & $\begin{array}{l}\text { Not } \\
\text { important }\end{array}$ & $\begin{array}{l}\text { Marginal Effects } \\
\text { Important }\end{array}$ & $\begin{array}{l}\text { Very } \\
\text { Important }\end{array}$ \\
\hline government & $-0.8909786^{* * *}$ & 0.4102541 & 0.1308898 & 0.1834655 & 0.6856107 \\
\hline qualityoflife & $0.7135886^{* * *}$ & 2.041304 & 0.1133749 & 0.1977375 & 0.6888877 \\
\hline energy & $0.7930811 * * *$ & 2.210196 & 0.107809 & 0.1951126 & 0.6970784 \\
\hline innovinfra & $-0.4033593 * * *$ & 0.668072 & 0.1450728 & 0.1771614 & 0.6777657 \\
\hline innovviewcity & $0.4061972^{* *}$ & 1.501099 & 0.1340429 & 0.180893 & 0.6850641 \\
\hline _cut1 & 3.799707 & & & & \\
\hline _cut2 & 5.327584 & & & & \\
\hline Log likehood & -97.896565 & & & & \\
\hline Pseudo $R^{2}$ & 0.2287 & & & & \\
\hline LR chi2 & 58.06 & & & & \\
\hline
\end{tabular}

Note: $* * * * * *$ represent the significance levels of $1 \%, 5 \%, 10 \%$, respectively

First of all, Pseudo $\mathrm{R}^{2}$ expresses that the model interprets the $22.87 \%$ of the agreement for 
this opinion. From the variables which used, the value of quality of life, the value of energy savings and the value of the improvements in the city's appearance through innovations seem to be important factors with a positive effect on how important respondents find the value of environmental sustainability. On the other hand, the value of satisfaction of the municipal administration and the value of improvements in infrastructure were variables with negative effect in the above opinion. All the variables were statistically significant at a significance level of $1 \%$ except of the variable innovviewcity (sectors which innovations can bring improvements) that are at a significance level of $5 \%$.

About the odd ratio, a person who is pleasured with the public administration is more likely at 0.41 (approx.) doesn't affect the opinion on the value of environmental sustainability compared someone who has a different opinion. The same thing happens if a person who believes that innovation can bring improvements in infrastructure is more likely by 0.67 (approx.) not to be influenced by the opinion about the value of environmental sustainability compared with someone who has a different opinion. In the remaining variables, the odds ratios are greater than one, so the situation is different in those cases. For example, a person who considers that the value of quality of life is important is more likely by 2.041 (approx.) affecting the opinion about the value of environmental sustainability compared with someone who doesn't consider it so important. The same thing happens if someone considers the significant value of energy savings are more likely by 2.22 (approx.) be affected as well if someone considers that innovation can bring improvements to city's appearance ( odd ratio= 1.51( approx.)).

In the next table, there are the marginal effects for each variable separately. The results between the variables have minor differences for each of the three options. For the entire model, the probability for selection not important where the remaining variables are at their average values is $14.35 \%$, the probability of selection important is $17.99 \%$ and the probability of very important is $67.65 \%$. Especially, the variable energy affects the dependent variable most of all. Table 2 describes the marginal effects for the cases not important, important and very important when respondents has given in the variable energy the value $1=$ not important and the value $5=$ very important.

Table 2. Marginal effects on non-important, important and very important when the variable energy respondent has given value of $1=$ not important and value $5=$ very important

\begin{tabular}{lll}
\hline & Margin energy & \\
& Value=1 & Value=5 \\
\hline Not Important & $\mathbf{0 , 4 9 0 0 0 7 3 4}$ & 0,0569148 \\
Important & 0,2903492 & 0,1260476 \\
Very Important & 0,2195774 & $\mathbf{0 , 8 1 7 0 3 7 6}$ \\
\hline
\end{tabular}

It's obvious that the chance to answer not important for the value of environmental sustainability someone who considers that the value energy saving is not important, is $49 \%$ 
when the other variables are at their mean values. The opposite is the case that considers energy saving very important, then the probability to reply not important is much lower $(5.69 \%)$ while the probability to answer very important is $81.7 \%$. In summary, the variable energy affects positively or negatively how important respondents find the value of the environmental sustainability.

4.2.2 Determinants Influencing Satisfaction of Respondents on the Quality of City Life

The functional expression of the logistic regression that estimated is:

$$
\text { qualitylife }=b_{0}+b_{1 \text { emploppor }}+b_{2 \text { envirawar }}+b_{3 \text { knowsmartcity }}+b_{4} \text { innovsmartcity }+\varepsilon_{i}
$$

\section{In which:}

qualitylife Dependent dummy variable which takes the value 0 if the respondent is not satisfied with the quality of city life and the value 1 otherwise.

emploppor Independent dummy variable which takes the value 0 .

if respondent considers that there are no employment opportunities and value 1 otherwise.

enviawar Independent dummy variable, which takes the value 0 if the respondent believes that there, is no environmental awareness in the city and the value 1 otherwise.

knowsmartcity Independent dummy variable, which takes the value 0 if the respondent does not know the phrase smart city and the value 1 otherwise.

innovsmartcity Independent dummy variable, which takes the value 0 if the respondent does not consider significant innovation in intelligent city and the value 1 otherwise.

$\boldsymbol{\varepsilon i}$ expresses regression estimation errors.

Table 3. Results of the logistic regression

\begin{tabular}{llll}
\hline Variables & Estimated Coefficients & Odd Ratio & $\mathrm{e}^{\beta-1}$ \\
\hline Constant & $-1.012^{* * *}$ & - & - \\
emploppor & $.974^{* *}$ & 2.934 & 1.934 \\
enviawar & $1.079^{* * *}$ & 3.571 & 2.571 \\
smartcity & $-.845^{* *}$ & 0.727 & -0.273 \\
innovsmartcity & $-1.576^{* * *}$ & 0.284 & -0.716 \\
$R^{2}$ (Nagelkerge) & .239 & & \\
2Log likehood & 147.077 & & \\
Hosmer and Lemeshow & 1.023 & & \\
\hline
\end{tabular}

Note: $* * *, * * *$ represent the significance levels of $1 \%, 5 \%, 10 \%$, respectively

The Hosmer - Lemeshow test, which uses statistical $\hat{C}$ to permit the goodness of fit of the data, emerged that in a statistical significance level of $5 \%(\chi 2=1,023, \alpha=0,961)$ there was a good fit of the model to the data and so a good fit in the percentage distribution of the 
observation in groups. Also the value of $\mathrm{R}^{2}$ (Nagelkerke) is 0.239 which explains that the $23.9 \%$ of the probability to occur the possibility that the respondent is pleased with the quality of city life. From the variables, which used, the employment opportunities and the existence of environmental awareness seem to be important factors with positive impact of satisfaction of the quality of city life. On the other hand, the knowledge of the phrase smart city, as also the importance of innovation in a smart city impact negatively in the dependent variable. All the variables are statistical significant at a level of $1 \%$ except of the variables smartcity and emploppor which are statistical significant at a level of 5\%. It's understood from the results that someone who believes that there are job opportunities in the city is pleased with the quality of the city life and also believes that there is environmental awareness. Different opinion has someone who knows the phrase smart city, as well as considers innovation important for this, is less satisfied with the quality of city life. The knowledge around the smart city influenced the opinion about the quality of city life.

About the odd ratio of the model, the variables smartcity (0.727) and innovsmartcity (0.284), the odd ratio are smaller than 1 , so they collect less likely to happen the possibility to be pleased with the quality of city life, having also negative impact to the dependent variable. Conversely, variables emploppor and enviawar are greater than 1, so they collect more likely to happen the possibility, having positive effect to the dependent variable. Specifically, the odd ratio for the variable emploppor is 2.939 and the marginal effect $1.939\left(\mathrm{e}^{\beta-1}=2,939-1=\right.$ 1,939). This means that the chance of someone to be satisfied with the quality of city life compared with variable emploppor is increased by $19.39 \%$, while the other entire variables are constant. Besides, the odd ratio for the variable envirawar is 3.571 and the marginal effect $2.571\left(\mathrm{e}^{\beta-1}=3,571\right.$ to $\left.1=2,571\right)$. This means that the chance of someone to be satisfied with the quality of city life compared with the variable enviawar is increased by $25.71 \%$, while the other entire variables are constant. In this model, the variable enviawar has the strongest effect.

\section{Conclusion}

To sum up, the purpose of the study was to highlight the characteristics of smart cities and become a comprehensive reference of the strategies that have been used around the world with the purpose of development of cities and ensure their sustainability in the future. The creation of smart cities based on specific factors: economy, mobility, administration, environment, human resources, quality of life. It's clear that they are directly connected to each other and must evolve together.

The results of the research about smart cities in the case of Kalampaka were particular interesting. There was a good level of information about them and paid attention to the quality of life, environmental sustainability, innovation and digital technology, which as mentioned in the cases of Lee et al (2012; 2014), Yamagata et al (2013), Batagan (2012), Ferrara (2015) and the project city keys of the European Commission (2015) play an important role in a smart city. It's indicative that another sector that should be given priority in a smart city is to protect the environment, as stated Ferrara (2015) and Kumar (2015). The results showed that environmental awareness in the city is not high and the aids in the part of 
recycling with events on the environment are necessary. The value of environmental sustainability seems to be affected, as shown the survey results, by the quality of life, the way that the administration works, the energy savings and innovation that may be made to the infrastructure and the image of the city. Great concern exists about the administration and the respondents believe that it should have greater participation in public life and to favor methods such as online services to serve better the citizens, as also reported by Kolokythas et al (2013). Similar results had the question about the quality of life, with health facilities be considered a high priority, as stated by Letaifa (2015) and seem to be affected by employment opportunities in the city, the environmental awareness and the knowledge about smart city and innovation. It's obvious that the sample knew about smart cities and their characteristics and through the answers given, shows the requirements which have from the city.

In conclusion, a smart city project was quite difficult to operate in the study area. It should be helped by local communities and administration, to exploit and refine existing capabilities. Tourism is a big advantage of the city which could generate profits, both in business and in society itself. Innovative ideas that will attract the interest of citizens and external factors. Examples of Greek cities, which head in this direction, are Trikala, Heraklion, and Larissa etc, trying to keep the new era in each one and attract potential investors. In terms of research, it's proposed to make an effort to study similar cases with cities which are potentially smart cities, recording a sample of citizen's opinions. Besides, such a project could be implemented in every city, as long as there are those characteristics, appropriate conditions and of course the will of all those involved in it.

\section{References}

Angelidou, M. (2016). Four European Smart City Strategies. International Journal of Social Science Studies, 4(4), 18-30. https://doi.org/10.11114/ijsss.v4i4.1364

Arduin, P., Negre, E., \& Rosenthal-Sabroux, C. (2016). Knowledge and Decision for Smart Cities Initiatives -Cases of Paris and Nice. 2016 International Conference on Industrial Informatics and Computer Systems (CIICS). https://doi.org/10.1109/ICCSII.2016.7462421

Batagan, L. (2012). Methodologies for local development in smart society. Oeconomics of Knowledge, 4(3), 23-34.

Borsekova, K., Petrikova, K., \& Vanova, A. (2015). Building of smart cities in specific conditions of transitional economies. ERSA conference paper, Lisbon 26.-29. https://doi.org/10.1016/j.sbspro.2016.05.289

Ferrara, R. (2015). The Smart City and the Green Economy in Europe: a Critical Approach. Energies, 8(6), 4724-4734. https://doi.org/10.3390/en8064724

Florida, R. L. (2002). The rise of the creative class: and how it's transforming work, leisure, community and everyday life. New York: Basic Books. https://doi.org/10.1007/978-3-319-55264-4_2 
Harrison, C., \& Donnelly, A. (2011). A theory of Smart Cities. 55th Annual Meeting of the International Society for the Systems Sciences. Held at University of Hull Business School, UK, July 17-22, 2011

Hollands, R. (2008). Will the real smart city please stand up? City: Analysis of Urban Trends, Culture, Theory, Policy, Action, 12(3), 303-320. https://doi.org/10.1080/13604810802479126

Hu, S., Brakman, S., \& Van Marrewijk, C., (2014). Smart Cities are Big Cities. CESifo Working Paper Series 5028, CESifo Group Munich.

Keta, M. (2015). Smart City, Smart Administration and Sustainable Development. Romanian Economic and Business Review, 10(3), 43-56.

Kolokytha, E., Kolokythas, G., Valsamidis, S., \& Florou, G. (2013). The contribution of the open data to the development of the smart cities. Scientific Bulletin - Economic Sciences, 14(2), 3-16.

Komninos, N. (2006). The architecture of intelligent cities: integrating human, collective and artificial intelligence to enhance knowledge and innovation. 2nd IET International Conference on Intelligent Environments (IE 06). https://doi.org/10.1049/cp:20060620

Kontinakis, N., \& De Cunto, A. (2015). Overview of the needs-City keys. D1.1project report, 2015. Retrieved from http://www.citykeys-project.eu/citykeys/cities_and_regions/Project-Deliverables

Ksherti, N., Alcantara, L. L., \& Park, Y. (2014). Development of a Smart City and its Adoption and Acceptance: the Case of New Songdo. Communications \& Strategies, 96, $113-128$

Kumar, S. (2015). Engendering Live able Low-Carbon Smart Cities in Asian as an inclusive Green Growth Model and opportunities for regional cooperation. Eria Discussion Paper Series.

Lee, J., Hancock, M., \& Hu, M. (2014). Towards an effective framework for building smart cities: Lessons from Seoul and San Francisco. Technological Forecasting and Social Change, 89(2014), 80-99.

Lee, J., Phaal, R., \& Lee, S., (2012). An integrated service-device technology roadmap for smart city development. Technological Forecasting and Social Change, 80(2013), 286-306.

Letaifa, S. B. (2015). How to strategize smart cities: Revealing the Smart model. Journal of Business Research, 68(7). https://doi.org/10.1016/j.jbusres.2015.01.024

Mochianakis, K. (2016). Designing smart cities in Greece: The case of Heraklion. Retrieved from http://www.citybranding.gr

Oppenheim, A. (1992). Questionnaire Design. Interviewing and Attitude Measurement, London. https://doi.org/10.1002/casp.2450040506 


\section{Macrothink}

Journal Title International Journal of Regional Development

ISSN 2373-9851 2018, Vol. 5, No. 1

Pham, C. (2015). Tokyo smart City Development in Perspective of 2020 Olympics: Opportunities for EU-Japan Cooperation and Business Development. EU-Japan Centre for Industrial Cooperation, Minerva EU-Japan Fellowship. Retrieved from https://www.eu-japan.eu/sites/eu-japan.eu/files/Smart2020Tokyo_Final.pdf

Poloncarz, M. (2013). Initiatives for a smart economy. Erie County Division of Information and Support Services.

Yamagata, Y., \& Seya, H. (2013). Simulating a future smart city: An integrated land use-energy model. Applied Energy, 112, 1466-1474. https://doi.org/10.1016/j.apenergy.2013.01.061

\section{Copyright Disclaimer}

Copyright for this article is retained by the author(s), with first publication rights granted to the journal.

This is an open-access article distributed under the terms and conditions of the Creative Commons Attribution license (http://creativecommons.org/licenses/by/3.0/). 